\title{
What nymphal morphology can tell us about parental investment - a group of cockroach hatchlings in Baltic amber documented by a multi-method approach
}

\author{
Marie K. Hörnig, Andy Sombke, Carolin Haug, \\ Steffen Harzsch, and Joachim T. Haug
}

\begin{abstract}
We describe a piece of Baltic amber, about 50 million years old, which contains a group of 13 small cockroach nymphs. These specimens were documented with different methods to explore the advantages and limitations of certain imaging techniques: (1) light-based methods, such as stereo-macro photography, composite imaging under polarised light, combined with virtual surface reconstruction, and (2) X-ray micro-computed tomography, processed as volume renderings and surface reconstructions. All nymphs within the amber piece are of the same size and do not exhibit any noticeable morphological variance. Their developmental state and the way in which they are arranged indicate that these nymphs represent hatchlings. Dictyopterans (including Mantodea and Blattodea with Isoptera as ingroup) exhibit a wide range of different types of social and brood care behaviour. The evolution of this complex set of characters has been addressed repeatedly in extant-based approaches, yet deep-time aspects of this evolutionary process have rarely been addressed. The specimens described here could represent a case of a group of blattodean nymphs hatching from an ootheca, which would represent the first fossil record of such a process, or even possibly provide the first indirect evidence of social behaviour in fossil non-termite dictyopterans, indicating that it was already developed 50 million years ago.
\end{abstract}

Marie K. Hörnig. Ernst-Moritz-Arndt-University of Greifswald, Zoological Institute and Museum, Cytology and Evolutionary Biology, Soldmannstr. 23, 17487 Greifswald, Germany. Marie.Hoernig@palaeo-evodevo.info Andy Sombke. Ernst-Moritz-Arndt-University of Greifswald, Zoological Institute and Museum, Cytology and Evolutionary Biology, Soldmannstr. 23, 17487 Greifswald, Germany. andy.sombke@uni-greifswald.de Carolin Haug. LMU Munich, Biocenter, Department of Biology II and GeoBio-Center, Großhaderner Str. 2, 82152 Planegg-Martinsried, Germany. carolin.haug@palaeo-evo-devo.info

Steffen Harzsch. Ernst-Moritz-Arndt-University of Greifswald, Zoological Institute and Museum, Cytology and Evolutionary Biology, Soldmannstr. 23, 17487 Greifswald, Germany. steffen.harzsch@unigreifswald.de Joachim T. Haug. LMU Munich, Biocenter, Department of Biology II and GeoBio-Center, Großhaderner Str. 2, 82152 Planegg-Martinsried, Germany. joachim.haug@palaeo-evo-devo.info

Hörnig, Marie K., Sombke, Andy, Haug, Carolin, Harzsch, Steffen, and Haug, Joachim T. 2016. What nymphal morphology can tell us about parental investment - a group of cockroach hatchlings in Baltic amber documented by a multi-method approach. Palaeontologia Electronica 19.1.6A: 1-20

palaeo-electronica.org/content/2016/1405-amber-cockroach-nymphs

Copyright Palaeontological Association, February 2016 
Keywords: fossilised behaviour; palaeo-evo-devo; Dictyoptera; documentation methods; micro-CT

\section{INTRODUCTION}

\section{Background: Fossil Behaviour}

Fossil remains of organisms provide an important source of knowledge about organisms that lived in the past, but which are extinct today. With this, fossils are an important source of knowledge for evolutionary reconstructions. Especially for understanding character transformation, fossils can shed light on evolutionary transitions of morphological structures (e.g., Haug, J.T., et al., 2010, 2012a, in press). Yet, information provided by fossils is not exclusively limited to aspects of morphology. Usually, fossils provide only little information about the behaviour of once-living organisms but there are certain exceptions. For example, trace fossils provide insights into behavioural traits, but they are often difficult to link to specific body fossils (Johnson et al., 1994; Braddy and Briggs, 2002; Shear and Edgecombe, 2010; Minter et al., 2012). Nevertheless, in a few cases also a more direct connection of body fossil and behaviour is preserved. Especially amber is well suited to highlight behavioural aspects in direct correlation to a body fossil. When organisms are trapped in the viscid resin, they die so fast that they often fossilise in life-like conditions (Arillo, 2007). Hence, descriptions of specimens are available that show intraspecific or interspecific interactions or reactions, e.g., stress behaviour (Arillo, 2007). Examples of this kind of "frozen behaviour" were described by several authors, e.g., mating, oviposition, food transport, predator-prey interaction or parasitism (Arillo, 2007 and references therein).

Yet cases of the 'frozen behaviour' category are rare. Alternative approaches can be based on morphological comparisons to modern counterparts from which possibly similar behaviours in extinct organisms can be inferred. While this line of argumentation is not a general one applied in biological sciences (Haug and Haug, 2014), it is a useful tool in historical sciences (which includes deep time discussion of palaeontological and biological research). Principle concepts of such an approach are addressed as the 'smoking gun' practice (Cleland, 2002). This means that the information we find today is used to reconstruct what happened in the past. Applying this concept to fossils aims at interpreting observed morphological details of the fossil individual in a behavioural context of modern forms (e.g., Haug, J.T., et al., 2013a).

\section{Background: Examples of Social Behaviour in the Fossil Record}

Within arthropods, different types of social behaviour can rarely be inferred in the fossil record, and even if, as the above mentioned examples demonstrate, usually uncertainties remain. Indirect phylogenetic evidence is the more common tool for addressing such questions. Only a few fossils with direct or indirect indications for social behaviour, mainly in the form of brood care behaviour, were described. An example for direct indication for brooding, and possibly further brood care, is a specimen of the Silurian ostracod Nymphatelina gravida, which is preserved with eggs and possible juveniles within its shield (Siveter et al., 2007). Specimens of trilobites preserved with supposed brood pouches were shown by Fortey and Hughes (1998). A further example is a pholcid spider carrying an egg sac preserved in Baltic amber; within these eggs, spiderlings close to hatching are visible (Weitschat and Wichard, 2002). Several specimens of Dominican and Baltic amber with inclusions of worker ants with larvae and pupae were depicted by Schlee (1980) and Weitschat and Wichard (2002).

A combination of phylogenetic and morphological argumentation can be applied to centipede myriapods: Representatives of Scutigeromorpha and Lithobiomorpha lay single eggs (plesiomorphic condition; Rosenberg, 2009), camouflage them with the aid of a specialised gonopodal claw and do not further care for their offspring. Fossils from the Silurian (Jeram et al., 1990) indicate an early origin of this strategy. Representatives of the unusually well-preserved Devonian centipede species Devonobius delta appear to lack the specialised gonopodal claw (Shear et al., 1998). This indicates that this species is either the sister species or an ingroup of Phylactometria, as all phylactometrians lack the gonopodal claw and perform extended brood care for the eggs and young. Therefore, brood care might be present since the Devonian within Chilopoda. A definite indication for brood care is provided by the phylactometrian species Mazoscolopendra richardsoni from the Car- 
boniferous Mazon Creek Lagerstätte (part of this discussion in Haug, J.T., et al., 2014).

A particularly strong though indirect phylogenetic argument for extended brood care is an ingroup position of a species in a monophyletic group of eusocial forms, as eusociality is lost only rarely (Kranz et al., 2002; Danforth et al., 2003). Examples of easily recognisable eusocial groups are ants, certain groups of bees and wasps and, especially interesting due to the close relationship to the present case, termites. The supposedly oldest evidence of the latter group (and putatively for eusociality as a whole) is a single specimen in amber from the early Cretaceous (Vršanský, 2010). The specimen has been treated as a 'eusocial cockroach', but also as an ingroup of termites (Vršanský, 2010, p. 796). Based on the available details it is not possible to clarify this issue, yet an ingroup position within termites is at least plausible, hence providing an indication of social interaction.

\section{Background: Amber}

While amber provides an exceptional form of fossil preservation, which is likely to facilitate the reconstruction of fossil behaviour, it also has some disadvantages. The documentation of animals preserved in amber can be challenging and still differs significantly from documenting extant specimens (see discussion in Hädicke et al., 2013). Hence, to extract the maximum of information from an amber fossil, the optimal method for each individual specimen needs to be determined (see discussion in Haug, J.T., et al., 2013b).

\section{Background: the Group in Focus}

Dictyoptera sensu lato is an ingroup of Neoptera, the insects that can fold their wings over the abdomen. Within Dictyoptera s.l., three general morphotypes are recognised: roach-like forms, mantodeans and termites. While nowadays the monophyly of Dictyoptera s.l. is generally accepted (e.g., Hennig, 1969; Beutel and Gorb, 2006; Klass and Meier, 2006), the internal relationships are still partly debated (Djernæs et al., 2012 and references therein). The most remarkable autapomorphy of Dictyoptera sensu stricto (sensu Béthoux et al., 2009, hence excluding numerous Palaeozoic roach-like insects) is the ability to generate oothecae (e.g., Klass, 1998; Bohn and Klass, 2003; Grimaldi and Engel, 2005; Klass et al., 2012). An ootheca is an egg-package which is produced in all modern cockroaches, mantodeans and the termite Mastotermes darwiniensis, the sister species to all other termites (Isoptera). Consequently, it must be concluded that the ability to produce oothecae is a plesiomorphic character retained from the stemspecies of Dictyoptera s.str., and that Isoptera (except M. darwinienis) lost this ability (e.g., Nalepa and Lenz, 2000; Klass and Meier, 2006; Ware et al., 2010). The oldest unequivocal and direct fossil evidence of such an ootheca was depicted by Grimaldi and Engel (2005). This putative representative of Blattellidae from the Cretaceous Crato Formation of Brazil is preserved with an ootheca still connected to the abdomen. Additional similar appearing specimens were reported by Hörnig et al. (2013). Only two other unambiguous fossil oothecae have been reported so far: one from the Late Cretaceous of Israel (Anisyutkin et al., 2008) and one specimen in Miocene amber (Poinar, 2010). Carboniferous oothecae have been described by Pruvost $(1919,1930)$ and Laurentiaux (1960). Yet, the interpretation of these fossils has been repeatedly questioned (e.g., Rasnitsyn and Quicke, 2002 and references therein; see also discussion in Hörnig et al., 2013).

The generation of an ootheca represents a basic type of care for the offspring, as the eggs are better protected than individually deposited eggs. Additionally, there is a wide range of more intense brood care adaptations and social behaviour within modern dictyopterans (e.g., Grandcolas, 1996, 1998; Park et al., 2002; Pellens and Grandcolas, 2003, Pellens et al., 2007). Adult females of different species of Blattodea carry the ootheca with themselves (Tallamy and Wood, 1986; Nalepa and Bell, 1997), retract the ootheca into a brood pouch ('ovovivipary'; Nalepa and Bell, 1997; Klass and Meier, 2006), or even internalise the complete brood care process ('vivipary'; Roth and Stay, 1961; Ingram et al., 1977; Tallamy and Wood, 1986; Grandcolas, 1996; Nelepa and Bell, 1997; Williford et al., 2004).

More extensive brood care behaviour that extends beyond the point of hatching is only possible if nymphs do not immediately disperse, i.e., with hatchlings that actively aggregate. This special type of social interaction restricted to survival, growth and development of the offspring is usually called 'subsociality' (Tallamy and Wood, 1986). It is thought to be a pre-requisite toward more complex behaviour (in the extreme case eusocial behaviour, which is characteristic for isopterans; Legendre et al., 2008).

This large variation of different brood care adaptations is important to be considered in evolutionary reconstructions of Dictyoptera s.str. The 
great variety of different degrees of brood care and social behaviour within Dictyoptera s.str. provides the opportunity to gain insights into the evolution of subsocial and eusocial behaviour in general. These different adaptations also have the potential to contribute to the reconstruction of the relationships within Dictyoptera s.str., as they represent complex characters.

We report here a first example of a fossil indication for nymphal social interaction of a 50 million year old cockroach. We see it as an important contribution to the reconstruction of the evolution of complex behaviour within Dictyoptera. As the fossils are preserved in amber, we additionally explore a wide range of documentation methods to extract the maximum information from these specimens.

\section{MATERIAL AND METHODS}

A single piece of amber with inclusions was investigated. The specimen with the collection number BSPG 1967 XX is housed in the Bayerische Staatssammlung für Paläontologie und Geologie, Munich, Germany. The amber piece was part of the former Scheele collection and is therefore supposed to be Baltic amber (Eocene, 40-50 Ma; Weitschat and Wichard, 2010). It comprises a group of blattodean nymphs and a nematoceran fly.

For morphological comparisons, a hatchling of the extant species Periplaneta americana and an early instar of the likewise extant species Blaberus craniifer were used. Specimens of Blab. craniifer and oothecae of $P$. americana were taken from the breeding at the Zoological Institute and Museum of the Ernst-Moritz-Arndt-University of Greifswald. Shortly after hatching, the nymphs of $P$. americana and Blab. craniifer were fixed in $70 \%$ ethanol and subsequently documented (see below).

Additional pieces of Baltic amber, each with an inclusion of single blattodean nymphs, were documented for comparison. Specimen PE 61065 is part of the collection of the Field Museum of Natural History (FMNH), Chicago. Specimen ZMUC 901795 is part of the collection of the Zoological Museum in Copenhagen (ZMUC).

The description of specimen BSPG 1967 XX, as well as that of the extant nymph of $P$. americana is provided as a descriptive matrix (Haug, J.T., et al., 2012b; Appendix 1).

\section{Light-based Documentation}

For photographic documentation, convexity, concavities and fissures of the surface of the amber piece were compensated by applying pure glycerol (Carl Roth GmbH + Co. KG, Karlsruhe, Germany) and by covering with a cover slip (Haug, J.T., et al., 2013b; Hädicke et al., 2013). In order to reduce reflections, polarisation filters were used in front of light sources and lenses (see e.g., Haug, C., et al., 2011). A Canon Eos Rebel T3i camera equipped with a MP-E $65 \mathrm{~mm}$ macro objective and a Macro Twin Lite MT-24 EX flashlight was used for overview images. To generate stereo images (red/ cyan), two photographs from different angles were recorded and then edited and arranged with Adobe Photoshop CS3 (see e.g., Haug, C., et al., 2011). Close-up images were taken using a Zeiss Axiophot compound microscope equipped with a Scopetek DCM 510 ocular camera. 2.5x and 4x objectives were used which resulted in $25 x$ and 40x magnifications. Up to 30 images in $60 \mu \mathrm{m}$, respectively, $30 \mu \mathrm{m}$ distance along the $z$-axis were taken and fused with Image Analyzer to produce consistently sharp images. Several image sections were stitched with the Photomerge function of Adobe Photoshop CS3. Based on the stacks, virtual surface reconstructions were calculated using Image Analyzer (see Haug, C., et al., 2011, 2013a; Haug, J.T., et al., 2012c, 2013b).

An early instar nymph of Blaberus craniifer and the head of a hatchling of Periplaneta americana were documented on a Keyence BZ9000 and a Nikon Eclipse 90i fluorescence microscope, respectively, under autofluorescence conditions. As described above, image stacks were recorded from different image details, fused with CombineZM/ZP, and stitched to receive a highresolution composite autofluorescence image (see Haug, J.T., et al., 2008, 2011).

\section{X-Ray Micro-computed Tomography and Reconstruction}

Micro-CT scanning was performed using a XRadia XCT-200 (Carl Zeiss Microscopy GmbH, Jena, Germany) equipped with switchable scintillator-objective lens units, which give the system a flexible field of view (details see Sombke et al., 2015). The sample was mounted on a stage and centred. Tomographies were performed using magnifications of $0.39 x$ and $4 x$ objectives with $X-$ ray source setting at $40 \mathrm{kV}$ and $8 \mathrm{~W}$ for $1 \mathrm{~s}$ acquisition time. Image stack properties were: (1) overview scan: system based calculated pixel size $=$ $33.6 \mu \mathrm{m}, 1024$ x 1024 px; (2) detail scan: system based calculated pixel size $=3.39 \mu \mathrm{m}, 1015 \times 1015$ px. Tomography projections were reconstructed using the XMReconstructor software (Carl Zeiss Microscopy $\mathrm{GmbH}$, Jena, Germany), resulting in 
image stacks (TIFF format). All scans were performed using Binning 2 and subsequently reconstructed using Binning 1 (full resolution) to avoid information loss.

Volume renderings were generated using Amira 5.6 (FEI, Hillsboro, OR, USA) and Drishti 2.4 (http://sf.anu.edu.au/Vizlab/drishti/index.shtml).

Manual surface reconstructions of the mouthparts of a single nymph were performed using Amira 5.6, exported as obj.-file and further processed in Blender (Garwood and Sutton, 2010; Haug, C., et al., 2011).

\section{RESULTS}

\section{Taxonomic Remarks}

The individuals described here are treated under open nomenclature, i.e., not attributed to a species, as the individuals most likely represent hatchlings (see below). Even among extant species we rarely have sufficient information about the morphology of the hatchlings; consequently the situation is worse in fossil species. We also do not want to introduce a new name for the here described individuals, which quite likely would need to be synonymised with a corresponding, already named adult later on. Assigning such early immature individuals to a specific sub-group of Dictyoptera s.str., or even a species, will demand for a reconstruction of ontogenetic sequences in fossil species combined with a rigid comparison to ontogenetic sequences of extant species. Detailed descriptions of ontogenetic sequences with focus of the morphology of the young, which are needed for the assignment to a specific subgroup, are not available in the literature for most arthropod species in general. Thus, as this is not the focus of the present study, a thorough systematic interpretation is clearly beyond our current scope.

\section{Description of Inclusions of Specimen BSPG 1967 XX}

The amber piece BSPG $1967 \mathrm{XX}$ includes an aggregation of at least 13 cockroach nymphs (Figure 1 ; because the nymphs are partly covered by each other, as well as other inclusions, the number of animals could only be determined by micro-CT data). Three nymphs are incomplete, which possibly is a result of the original preparation of the amber piece (grinding). All nymphs appear weakly sclerotised and have nearly the same body size. As an example, one nymph was investigated using micro-CT, 3D-reconstructed and measured (a complete detailed description of the specimens, as well as a hatchling of Periplaneta americana for comparison, is provided as a descriptive matrix; Appendix 1). The total body length (without appendages) of this representative nymph is about $2.5 \mathrm{~mm}$ and total body width (without appendages) about 0.8 $\mathrm{mm}$.

Head. The head capsule in dorsal view is dropshaped and about $0.8 \mathrm{~mm}$ long and $0.7 \mathrm{~mm}$ wide (without palps). Ocular segment and post-ocular segments 1-5 (insect terminology [IT]: antennal, intercalary, mandibular, maxillary and labial segment) are dorsally contributing to the head capsule. The head capsule is freely articulated against the next posterior segment.

Compound eyes appear to be absent (Figure 2 ). The clypeus is articulated distally to the head capsule and proximally with the labrum. The labrum is about $0.15 \mathrm{~mm}$ long and a little less than $0.2 \mathrm{~mm}$ wide. The appendage of post-ocular segment 1 (IT: antenna; arthropod terminology [AT]: antennula) is well developed, about $2.5 \mathrm{~mm}$ long and divided into 19 elements. Each element is about $0.15 \mathrm{~mm}$ long and $0.1 \mathrm{~mm}$ wide. The appendage of post-ocular segment 2 (IT: intercalary segment) is absent. Appendages of post-ocular segment 3 (mandibles) are well developed. Each one is about $0.2 \mathrm{~mm}$ long and $0.1 \mathrm{~mm}$ wide and medially covered by the labrum. The median extension of mandibular sternite (hypopharynx) is well developed. The hypopharynx is about 0.15 $\mathrm{mm}$ long and a little less than $0.1 \mathrm{~mm}$ wide. Appendages of post-ocular segment 4 (IT: maxilla; AT: maxillula) are well developed and prominent. The proximal central part (stipes) has two median endites; a proximal one (lacinia) and a distal one (galea). Disto-laterally an elongate structure (maxillary palp) arises from the stipes. The distal endite (galea) is about $0.3 \mathrm{~mm}$ long and $0.15 \mathrm{~mm}$ wide. The maxillary palp is equipped with setae and subdivided into five elements. The entire length of the maxillary palp is about $1 \mathrm{~mm}$. Appendages of postocular segment 5 (IT: labium; AT: maxilla) are medially conjoined and equipped with pronounced enditic median protrusions (pointing relatively anteriorly; paraglossa and glossa) and distal elongate structures (labial palps). The paraglossa is about $0.2 \mathrm{~mm}$ long and $0.1 \mathrm{~mm}$ wide. The labial palp is equipped with setae, subdivided into four elements and about $0.35 \mathrm{~mm}$ long.

Thorax. Post-ocular segments 6-8 (thoracic segments 1-3) each dorsally possess a separate, weakly sclerotised tergite (pronotum, mesonotum and metanotum). The pronotum is about $0.8 \mathrm{~mm}$ wide, slightly longer than $0.5 \mathrm{~mm}$ and is partly 


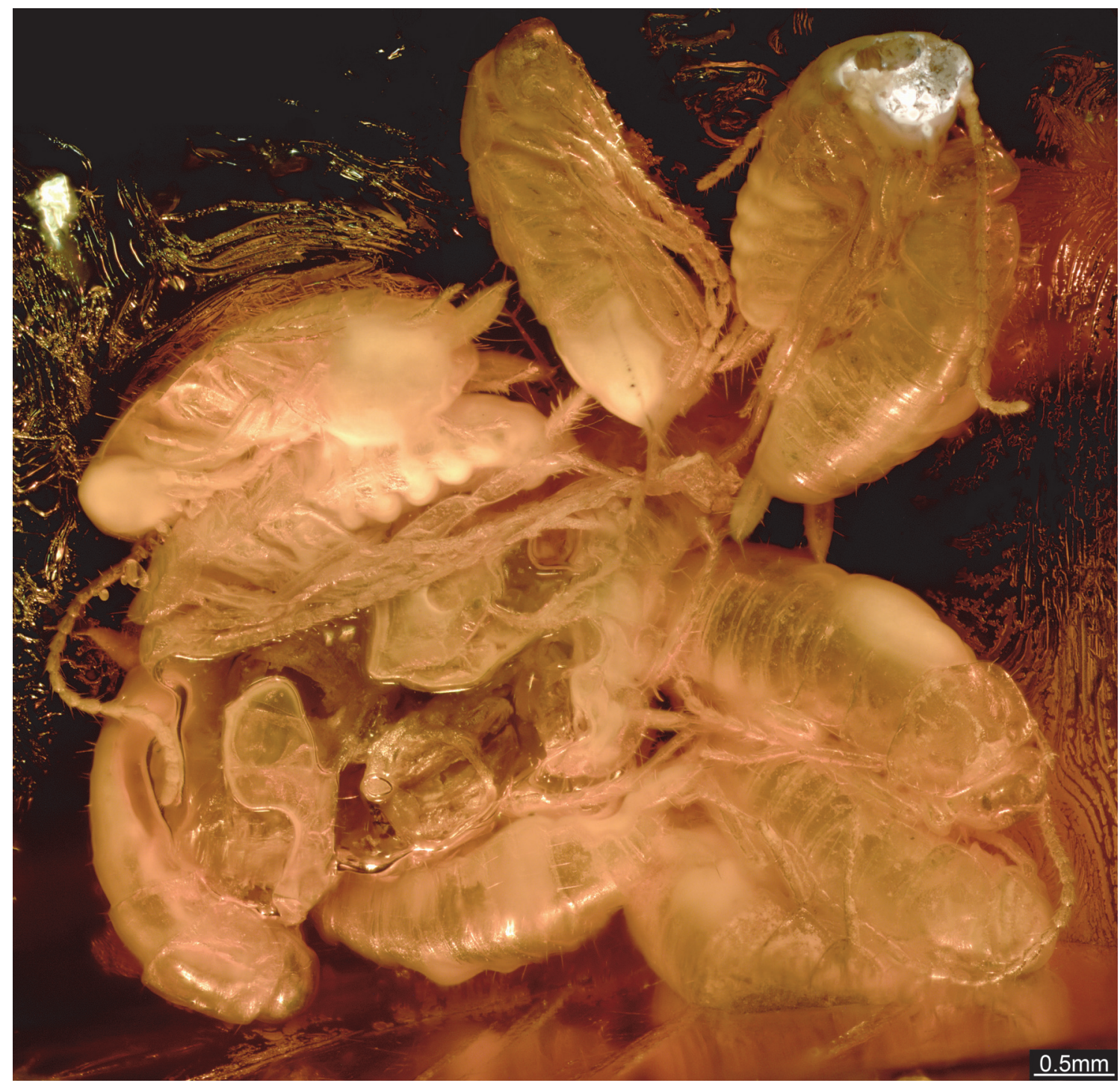

FIGURE 1. Overview of BSPG 1967 XX, part of the Bayerische Staatssammlung für Paläontologie und Geologie, Munich. Germany; documented with composite imaging. Single piece of Baltic amber with inclusion of 13 cockroach nymphs.

overhanging the head capsule (only the posterior region). The mesonotum is about $0.8 \mathrm{~mm}$ wide and $0.4 \mathrm{~mm}$ long. The metanotum is about $0.8 \mathrm{~mm}$ wide and $0.4 \mathrm{~mm}$ long. The entire length of the thorax is about $1.25 \mathrm{~mm}$. Appendages of post-ocular segments 6-8 (thoracic segments 1-3) are each divided into coxa, trochanter, femur, tibia, tarsus and pretarsus. The entire length of thoracic legs are: prothoracic leg about $2.3 \mathrm{~mm}$, mesothoracic leg about $2.5 \mathrm{~mm}$ and metathoracic leg about 3 $\mathrm{mm}$.

Abdomen. Post-ocular segments 9-16 (abdominal segments 1-8) dorsally possess a separate, weakly sclerotised tergite. Post-ocular segments 17-19 (abdominal segments 9-11) are not observ- able. The length of the abdomen (post-ocular segments 9-19) is about $1.2 \mathrm{~mm}$. Styli (appendages of post-ocular segment 17) are slightly curved and about $0.15 \mathrm{~mm}$ long. Appendages of post-ocular segment 19 (cerci) taper to a fine apex on the distal end and are about $0.5 \mathrm{~mm}$ long and at the base 0.1 $\mathrm{mm}$ wide.

\section{Preservation of the Specimen}

Amber pieces are often the results of several flows of liquid resin, which also seems to be the case here. At least two different flow events seem to have generated this piece, as recognisable by an apparent layer within the amber. This knowledge needs to be considered when interpreting the 


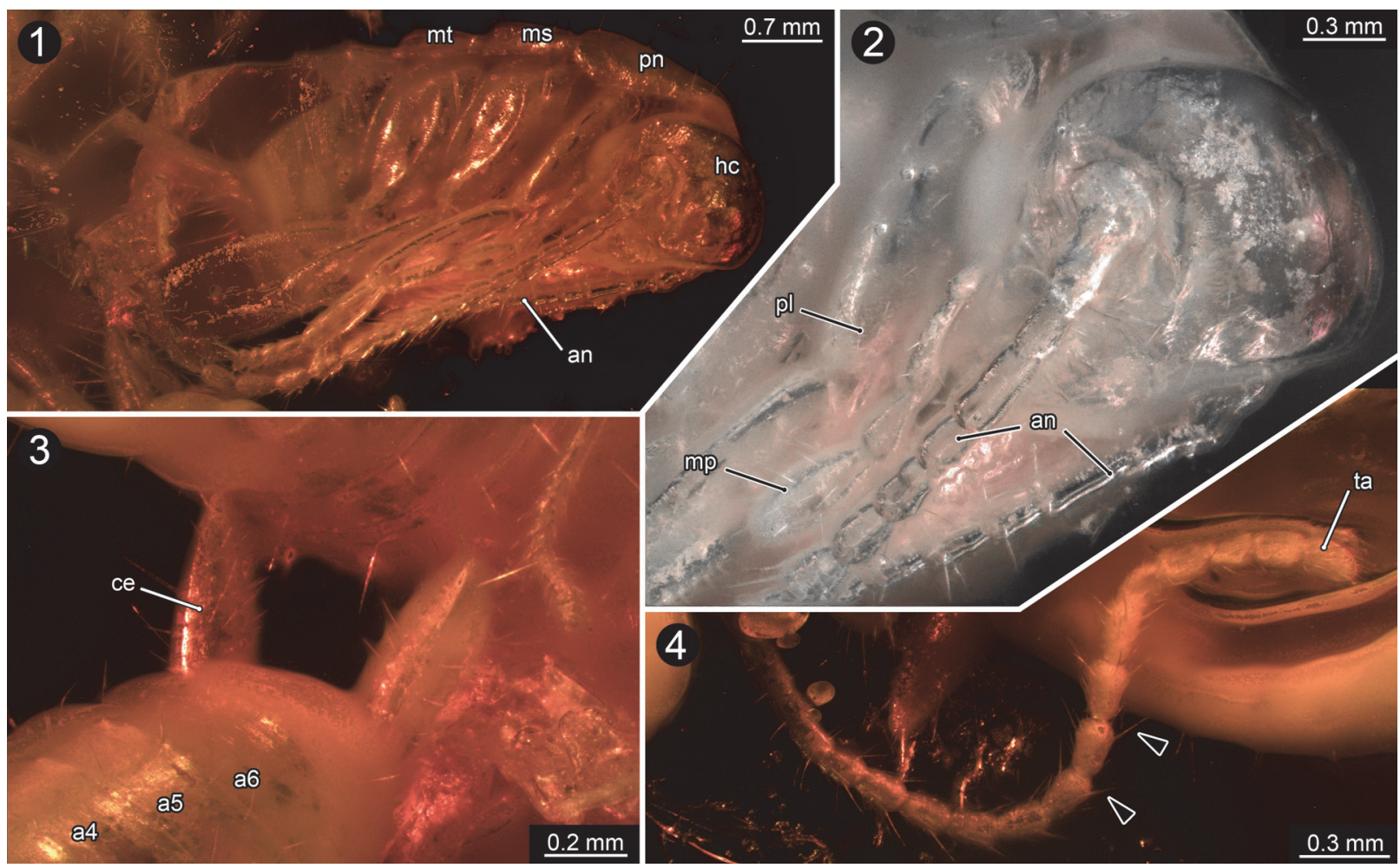

FIGURE 2. Close-ups of nymphs in amber (BSPG 1967 XX). 1, Overview of a single nymph (red-coloured specimen in Figure 4). 2, Head with antennae and maxillary palp equipped with setae of specimen in 1, compound eyes not observable. 3, Cerci equipped with setae (blue-coloured specimen in Figure 4). 4, Close-up of antenna equipped with setae (yellow-coloured specimen in Figure 4), arrows point to setae. Abbreviations: a4-a6, abdominal segments 4-6; an, antenna; ce, cercus; hc, head capsule; mp, maxillary palp; ms, mesonotum; mt, metanotum; pn, pronotum; $\mathrm{pl}$, coxa of prothoracic leg; ta, terminal article of the antenna.

specimens within the amber. For example, the antennae of the nymphs are partly held close to the body, which is a rather unusual position. Most likely the specimens became attached on top of the first resin flow, died and were then covered by a second flow. The event of death and the mechanical force of the second resin flow could have caused the specific position of the antennae and legs (further possible interpretation of position of legs and antennae in discussion below).

\section{DISCUSSION}

\section{Comparing Documentation Techniques}

Different documentation techniques provide different types of information and have different advantages and disadvantages. One of the principle advantages of light-based methods is that they can be applied to comparably large sample sizes because they are less time consuming. For applying X-ray based methods such as micro-CT, specimens have to be transported from their storage site to the imaging device, while light-based methods either rely on widely available (microscopes) or even transportable (camera set-ups) equipment and therefore permit to document a specimen right in the collection where it is housed. In the present case the single specimen could be loaned and sent to our lab, hence these two advantages of lightbased methods do not have any effect. Stereo imaging (with a camera) is an elegant way of providing topographic information (Figure 3 ) in a very fast way. The documentation of the specimens using a compound microscope has the advantage that finest details such as setae can be observed (Figure 2). With the procedure described by Haug, J.T., et al. (2013b), additional topological information can be gathered in such images. Both lightbased methods, macro- and micro-photography, also have the advantage to provide colour information, which is a quite important aspect because colour provides additional information about the degree of sclerotisation of the cuticle or the presence of compound eyes.

The advantage of using micro-CT is the possibility to generate a virtual reconstruction of the 

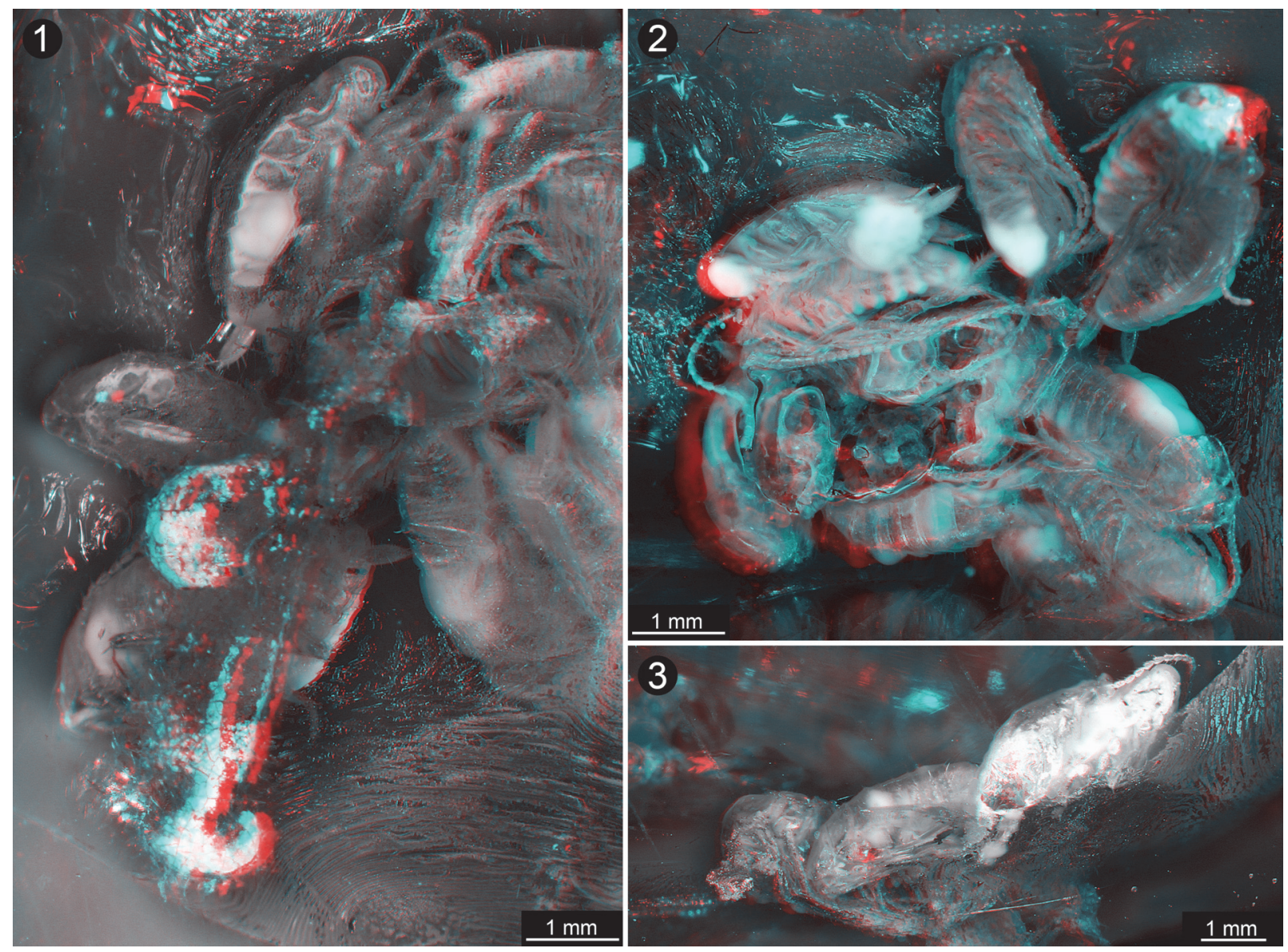

FIGURE 3. Overview of BSPG 1967 XX, documented with stereo imaging from all available sides of the specimen (13). Images presented as red-cyan stereo-anaglyphs; please use red-cyan glasses to view.

amber piece including the animals, which allows viewing from various perspectives that reach further than the virtual surface reconstruction (Figures 4 and 5). With light-based methods, viewing angles are usually limited (in contrast to extant specimens, see Figure 6), because in thin amber pieces often two sides are available; in thicker pieces often only one side can be observed. The lower side might also be concealed by secretions, excretions, and/ or gases, other inclusions, as well as distortions of surrounding resin due to movement of the specimen during the embedding process or caused by layering (summarised in Hädicke et al., 2013).

In the present case, the amber piece had been ground from three sides. Virtual surface reconstruction allows access of a few additional degrees while only virtual models based on the micro-CT data set allow viewing specimens from all possible angles. Additionally, micro-CT can allow a view inside the specimen (Figure 4). Although the individuals in the present case are 'hollow' and do not provide any internal details, concealed structures may in other cases become visible in the tomographies. In our study the tomography reveals a detailed overview of the mouthparts (Figure 7). Very small and thin structures such as setae can be visualised based on CT-data sets. Yet, this can be challenging due to the low absorption contrast between cuticula and amber. Fine details are visible in the virtual slides, but often cannot be visualised in volume renderings. In Amira, which is one of the often used software programs for CT-datasets, the setting possibilities of the array for rendering are restricted to displacements along the x-axis of the histogram. Only a combination of several different 'exposures' reveals the setae (Figure 8; comparable to methods from photography; Haug, C., et al., 2013b). A better option for visualisations based on CT-data sets with low contrast seems to be the open source software Drishti. Here, it is possible to choose arrays of the histogram more precisely along the $x$ and $y$-axis which allows a more detailed visualisation in such cases (Figure 9). Indeed, also render- 

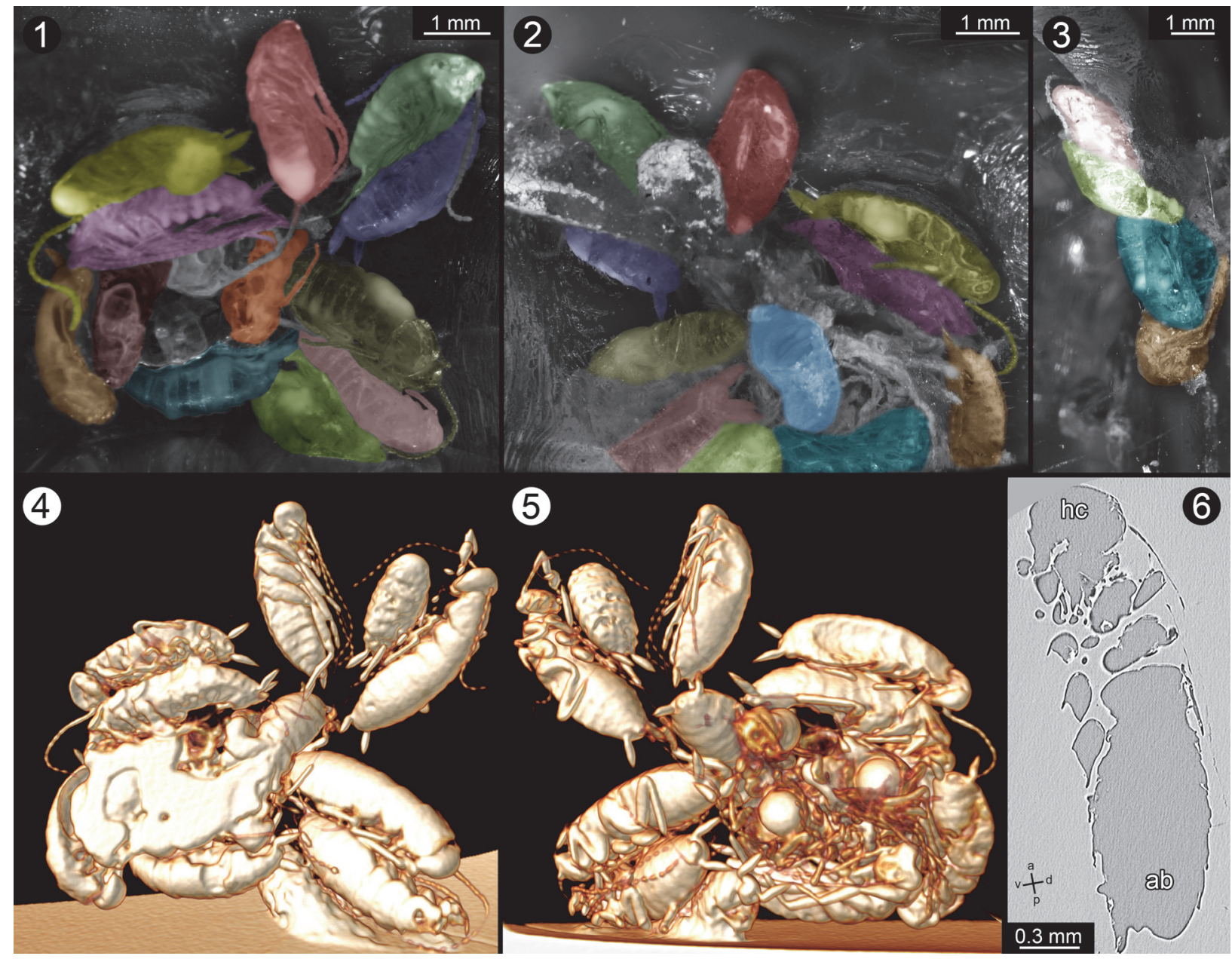

FIGURE 4. Overview images of BSPG 1967 XX. 1-3, Colour-marked versions of Figure 3 (different individuals marked in different colours, same individuals marked in same colour in different viewing angles). 4-5, Volume renderings based on micro-CT data (Amira) (different viewing angles in 4 and 5). 6, Tomographic section from micro-CT image stack (red-coloured specimen in 1 and 2), inner structures are not preserved.

ings in Drishti have limitations and, at this time, CT based renderings cannot display details at a scale as it is possible in microphotography.

In conclusion, all methods used here have their specific advantages and limitations. Therefore, only a combination of different methods allows the extraction of available details.

\section{Ascription to Dictyoptera}

The individuals enclosed in the amber piece are identified as early post-embryonic developmental stages of cockroaches, also known as nymphs (at least in anglo-american literature). The nymphs possess chewing mouthparts and dictyopteran-type cerci (about 3-4 times longer than wide; not curved, tapering distally; Figure 2). The cerci of dictyopterans are usually subdivided into several elements (e.g., Rasnitsyn and Quicke, 2002). How- ever, the cerci of the here described nymphs in amber appear to lack any subdivision, possibly because they represent an early developmental stage (see below). The identification of the nymphs as cockroaches is based on the morphology of the pronotum, which covers the head posteriorly. Also, specialised features of other dictyopteran ingroups are absent. For example, unlike in mantodeans, the foreleg is not elongated in proportion to midand hindleg, and all legs are equipped with numerous setae.

\section{Interpreting the Fossil}

A Case of Hatching? All cockroach nymphs described here have the same body size and are certainly at the same stage of development (Figure 1). Their small body size and their stage of development suggest that these nymphs represent 


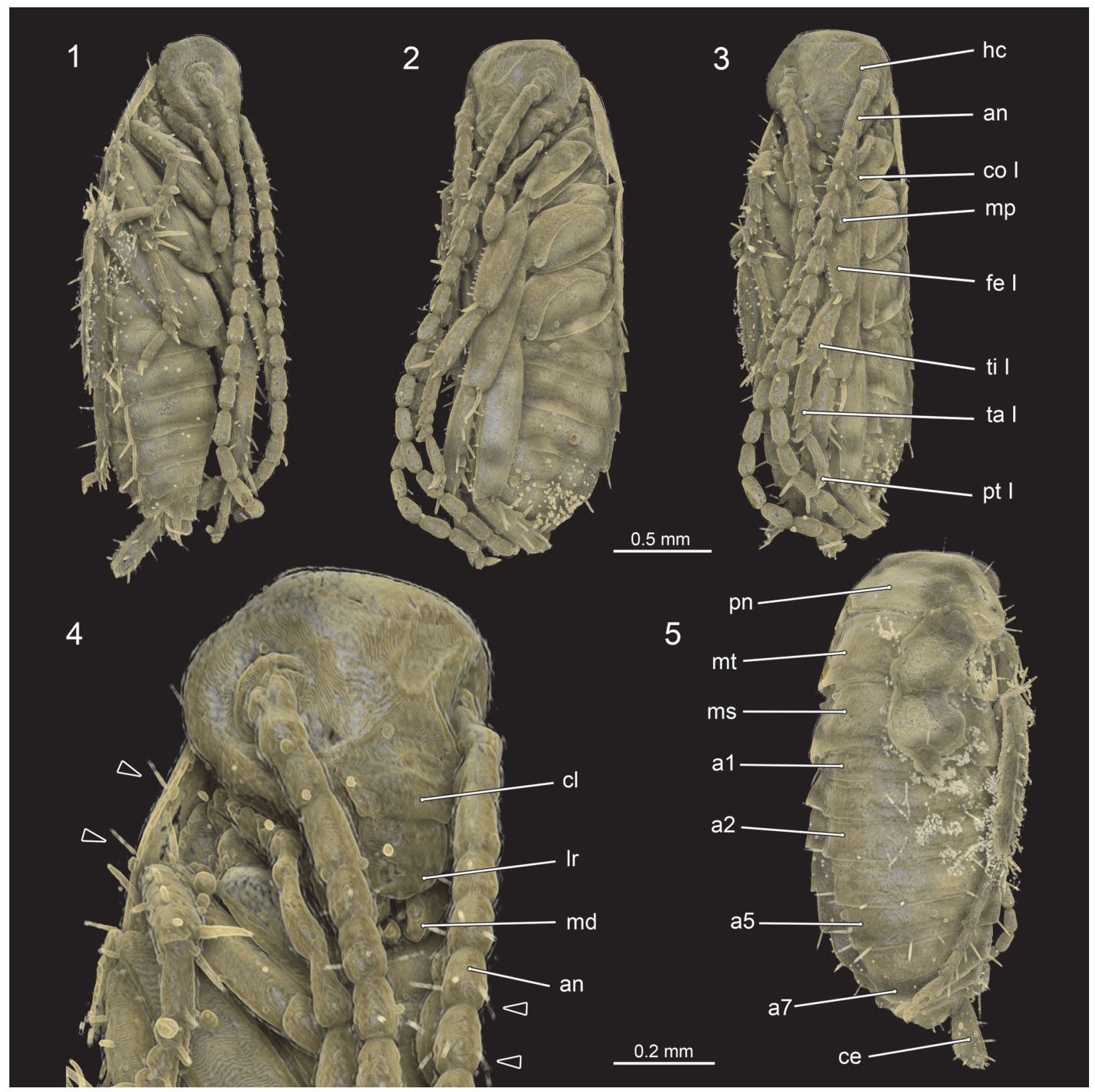

FIGURE 5. Volume renderings of one nymph of BSPG 1967 XX (red-coloured specimen in Figure 4) in about lateral (1-2), ventral (3-4), and dorsal (5) views generated with Drishti 2.4 based on micro-CT data. Abbreviations: cl, clypeus; co I, coxa of prothoracic leg; fe I, femur of prothoracic leg; Ir, labrum; md, mandible; pt I, praetarsus of prothoracic leg (tibial claw); ta I, tarsus of prothoracic leg; ti I, tibia of prothoracic leg; a1-a7, abdominal segments 1-7. Other abbreviations are the same as in Figure 2.

hatchlings. The absence of pigmentation may indicate that they hatched shortly before the resin inclusion. Shortly after hatching or moulting, the cuticle of insects is soft and unpigmented, but it hardens and darkens very fast. Indeed, the lack of pigmentation of the nymphs could be an effect of preservation conditions. Chemicals within the amber usually react with the fossil and may partly change its colouration, but it seems unlikely that the amber chemicals caused the complete absence of pigmentation. If this were the case, the amber itself probably would have darkened massively. Examples for well pigmented older nymphs from Baltic amber are shown in Figure 10.

There is no remnant of an ootheca preserved in the present specimen which would support the 


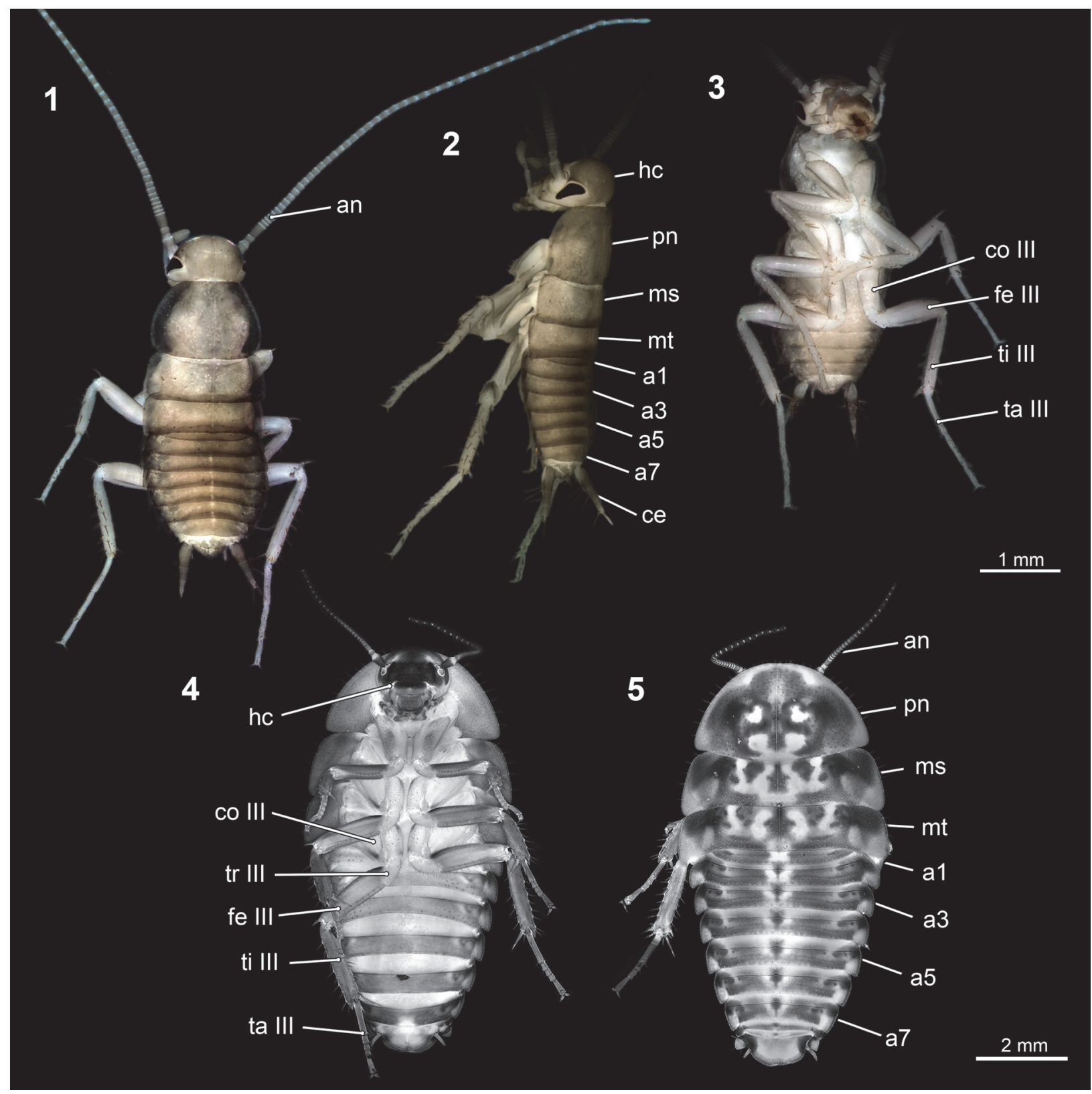

FIGURE 6. Nymphs of the extant species Periplaneta americana (1-3) and Blaberus craniifer (4-5). 1-3, Hatchling of $P$. americana in dorsal (1), lateral (2), and ventral (3) views documented with compound microscope. 4-5, Early instar nymph of Blaberus craniifer in ventral (4) and dorsal (5) views documented with composite autofluorescence microscopy. Abbreviations: co III, coxa of metathoracic leg; fe III, femur of metathoracic leg; ta III, tarsus of metathoracic leg; ti III, tibia of metathoracic leg. Other abbreviations are the same as in Figure 2 and 4.

interpretation of a recent hatching event. Yet, the position of legs and presumably antennae close to the body of some of the nymphs could be interpreted as folded as in an embryonic position, while other nymphs just started unfolding their appendages. These postures would support the interpretation of the nymphs as just hatching.

One could also argue that the nymphs belong to a species which performs ovipary or ovovivipary and that the specimens in fact represent late embryos; in such a case the mother could have been forced to release her offspring too early due to the threat of the amber. Yet, it is difficult to find positive support for such an assumption. If this would be the case, we would expect remains of an ootheca or that the embryos would be arranged in rows in accordance with the position of the young in the ootheca. Vivipary in general seems also 


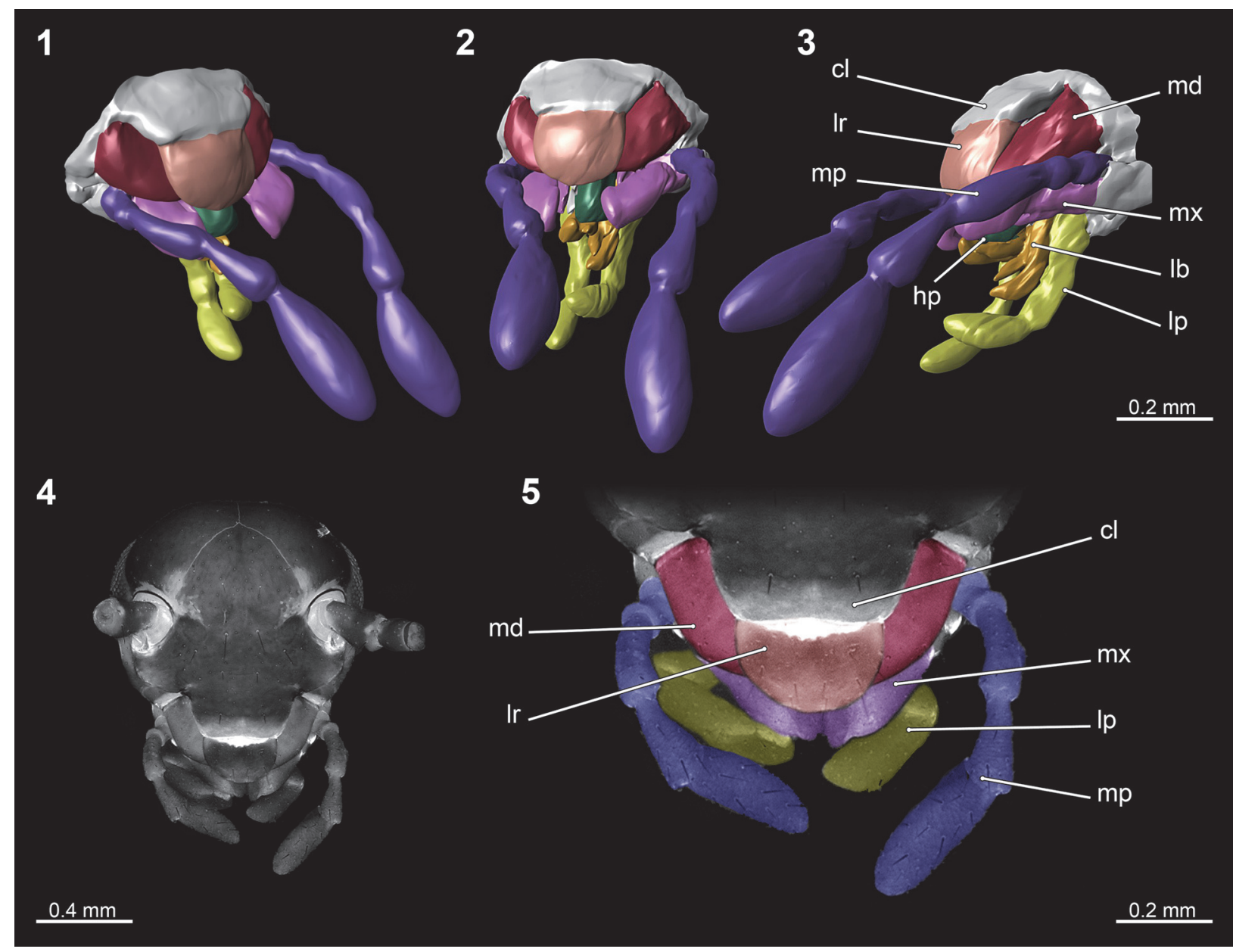

FIGURE 7. Comparison of mouthparts of one nymph of BSPG 1967 XX and first instar of Periplaneta americana. 1-3, Surface reconstruction of the mouthparts of one nymph in amber; based on micro-CT data. Same individual as in Figure 2, about lateral (1 and 3) and frontal (2) views. 4-5, Head with mouthparts of first instar nymph of $P$. americana; frontal view of the head (4) and colour-marked close-up image of the mouthparts (5), composite autofluorescence image. Abbreviations: hp, hypopharynx; lb, labium; Ip, labial palp; mx, maxilla. Other abbreviations are the same as in Figures 2 and 4.

unlikely, because there is just one viviparous blattodean species known so far, Diploptera punctata and nymphs of this species were described as relatively large (in relation to body size of the adults) and far developed when emerging from the mothers brood pouch (Nalepa and Bell, 1997). So far, hatchlings of insects have rarely been described in the fossil record (Haug, J.T., et al., 2015), including dictyopterans (Hörnig et al., 2014).

A Case of 'Nymphal Gregarism'? Cockroaches exhibit a wide range of different types of intraspecific behaviour reaching from solitariness, active gregarism of nymphs, over to gregarism of nymphs and adults to brood care behaviour such as feeding and protecting the offspring (Grandcolas, 1998; Legendre et al., 2008, 2014). Gregarious behaviour of nymphs ('nymphal gregarism') is dis- played by various species, e.g., Blattella germanica (see Ishii and Kuwahara, 1968; Ame et al., 2004), Lanxoblatta emarginata and Phortioeca nimbata (Legendre et al., 2008), and to a certain degree by Periplaneta americana (see Leoncini and Rivault, 2005). Various advantages for nymphs living in aggregations were summarised by Bell et al. (2007): protection against predators, enhanced availability of nourishment, ability to create a specific microenvironment (protection against water deficit), and beneficial group effects on development. Olfactory, visual, acoustic, or tactile stimuli, or various combinations of these may initiate the animal's aggregation. Chemical stimuli can be pheromones (Ishii and Kuwahara, 1967; Bell et al., 1972; Burk and Bell, 1973; Leoncini and Rivault, 2005), but also volatile and contact chemicals of 


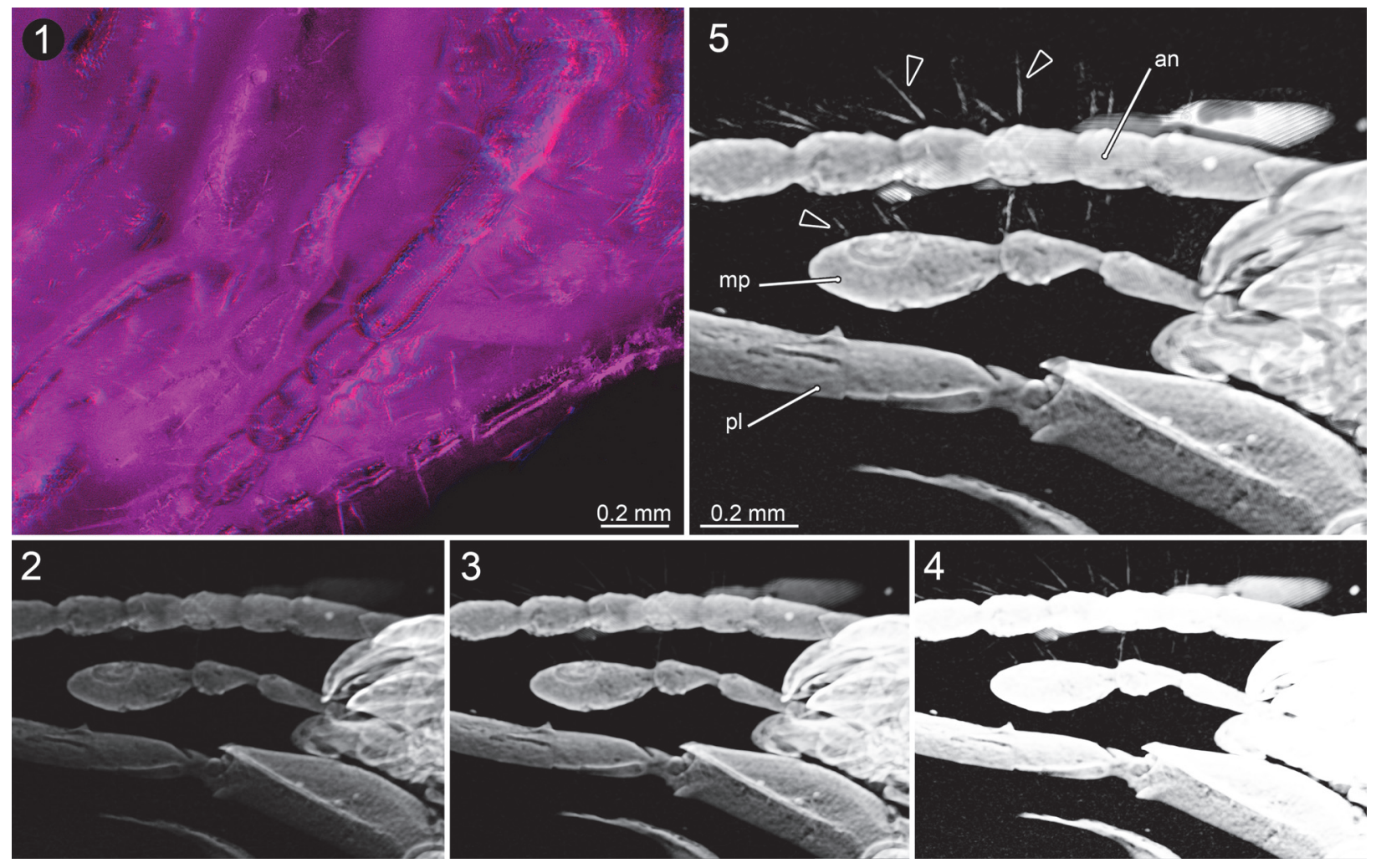

FIGURE 8. Close-ups of maxillary palp of one nymph of BSPG 1967 XX. 1, Palp of red-coloured nymph in Figure 4 documented with stereo imaging. Images presented as red-cyan stereo-anaglyphs; please use red-cyan glasses to view, red left, cyan right. 2-4, Close-ups of volume rendering of maxillary palp and part of antenna of red-coloured nymph in Figure 4; documented at three different grey values. 5, Combined version of 2-4, arrows point to setae. Abbreviations are the same as in Figures 2 and 4.

excrements (Sakuma and Fukami, 1990; Bell et al., 2007).

For the here described group of 13 enclosed cockroach nymphs we suggest a case of 'nymphal gregarism' behaviour. Yet, closely considering their morphology, some additional aspects are obvious: beside the lack of pigmentation, compound eyes are not clearly visible and antennae and cerci seem to be less developed due to relatively few subdivisions. Gregarious nymphs usually must be able to survive on their own. Considering their poorly developed sensory structures we therefore want to explore an additional possibility.

A Case of Brood Care? As pointed out above, 'nymphal gregarism' is thought to be a pre-requisite for a more complex brood care behaviour. This does not mean that all species that show nymphal gregarism also show extended brood care. However, if nymphs disperse immediately after hatching, extended brood care is impossible. The hatchlings of $P$. americana and the nymphs in amber are quite alike in body length and general morphology, but, seemingly in contrast to the nymphs in amber, the compound eyes of $P$. americana (as in most other cockroach species) are clearly recognisable being well developed and pigmented at hatching (Figure 6). The presence and mode of parental brood care behaviour is correlated with the developmental status of the hatchlings in extant cockroach species (Nalepa and Bell, 1997). The hatchlings of several extant (sub-) social species are blind and weakly sclerotised and dependent on shelter and feeding by their parents (Tallamy and Wood, 1986; Nalepa and Bell, 1997). Hatchlings with soft and unpigmented cuticle are more likely to be captured by predators such as ants or also conspecifics (cannibalism) (Nalepa and Bell, 1997).

In the case of the here described nymphs in amber, compound eyes are not detectable at all. This is very unlikely to be an artefact due to specific preservation as generally compound eyes in insects preserved in amber are very prominent (examples of cockroach nymphs with apparent eyes in Figure 10), suggesting that the compound eyes are not yet developed in this early stage. 


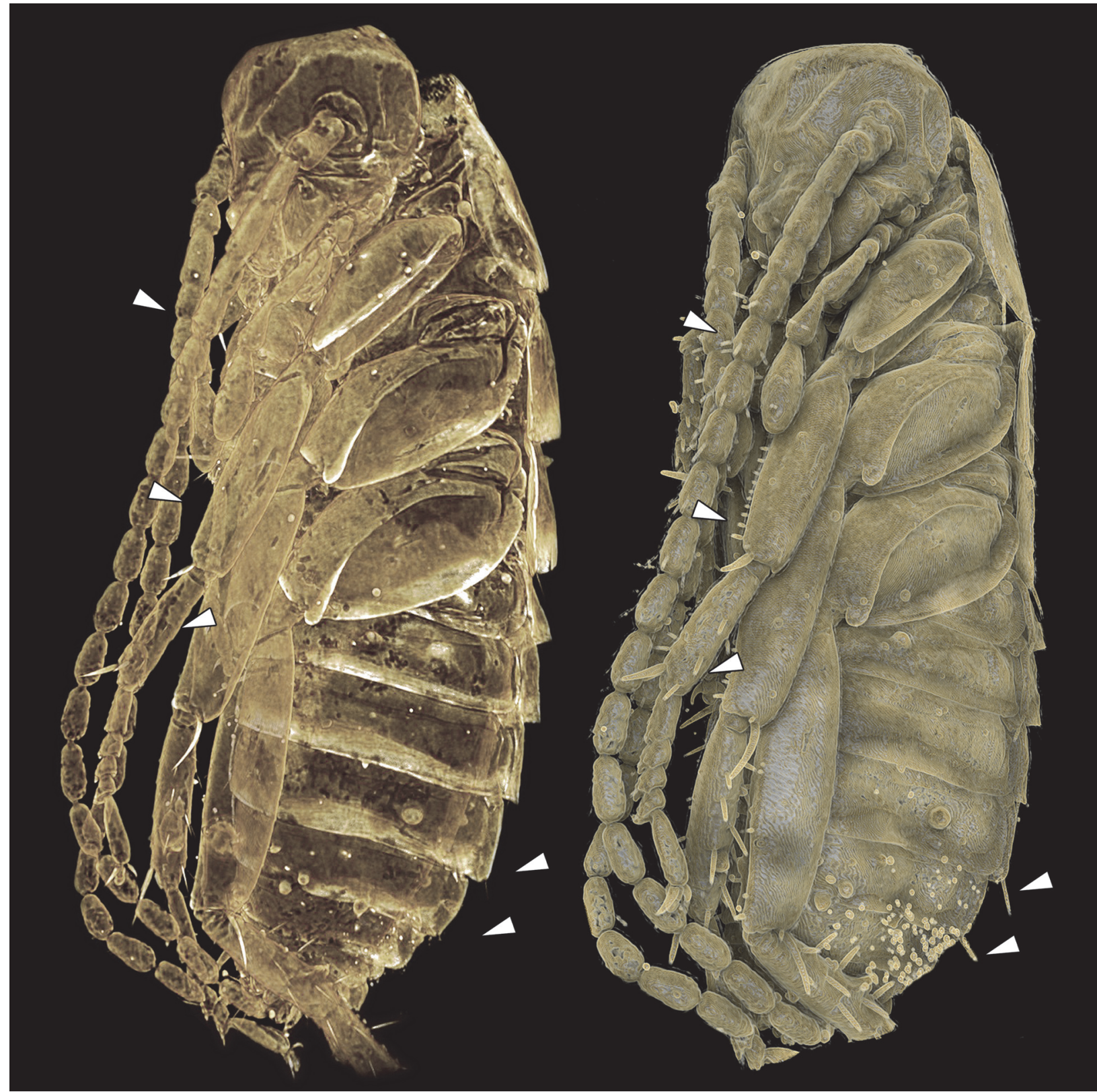

FIGURE 9. Comparison of volume renderings of one nymph of BSPG 1967 XX generated by Amira 5.6 (left) and Drishti 2.4 (right) (images with system based pseudocolour). Note especially the differences of the level of details in the marked areas (arrows).

Another character worth considering is the number of elements of antennae and cerci. The antennae of the nymphs in amber are composed of less than half of the number of elements of $P$. americana hatchlings (47 vs. 19), while the antenna of $P$. americana is just about a third longer than the antenna of the nymphs in amber (in relation to the body). Early instars of Blaberus craniifer exhibit nearly the same number of antennal elements, but the antenna is distinctly shorter (Figure 6 ). The notably lower number of the antennal and cercal elements, in relation to the length, indicates the less advanced developmental status of the nymphs in amber. During ontogeny, the number of antennal elements increases in polyneopteran insects (e.g., Hockman et al., 2009) and hence the low number found in this case indicates an immature state. For a clearer statement about a correlation of the number of antennal elements of the fossil species, it would be beneficial to know the adult antennal morphology, or at least that of more advanced nymphal stages. The cerci are entirely 

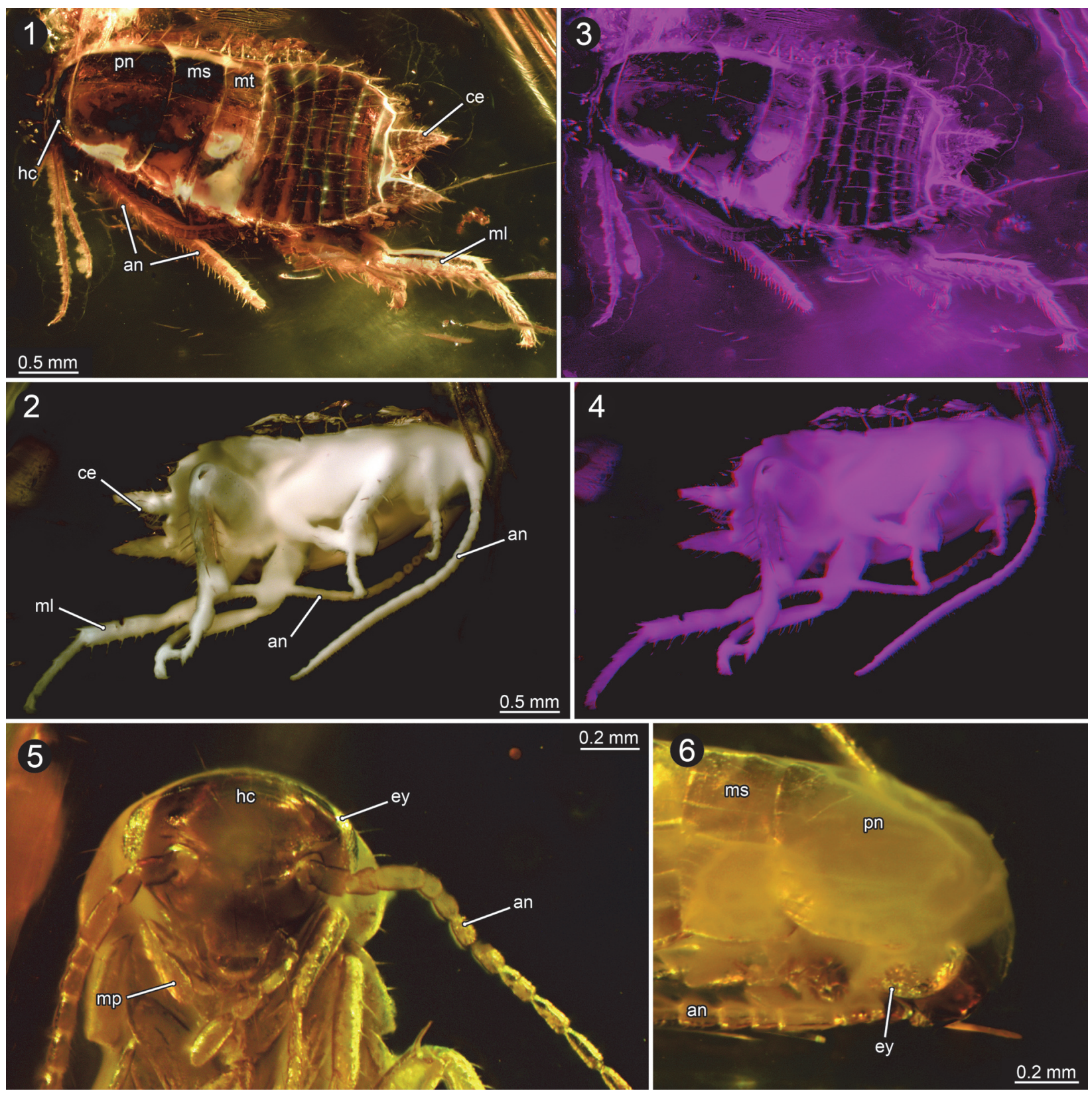

FIGURE 10. Blattodean nymphs in Baltic amber. 1-4, Specimen PE 61065, dorsal view (1), distinct pigmentation of cuticula visible; ventral view (2); and stereo-images of PE 61065 (3-4). Images presented as red-cyan stereo-anaglyphs; please use red-cyan glasses to view. 5-6, Specimen ZMUC 901795, close-up image of the head (5) and closeup image of the head lateral view (6). Abbreviation: $\mathrm{ml}$, femur of metathoracic leg. Other abbreviations are the same as in Figures 2 and 4.

lacking any subdivision. The early developmental state of antennae and cerci would be compatible with this species depending on brood care.

It has been shown that nymphs of certain species with brood care have elongated and specifically shaped mouthparts for feeding on excretions or maternal secretions (e.g., Cryptocercus punctulatus, Phlebonotes pullens, Perisphaerus sp.; Tal- lamy and Wood, 1986; Nalepa and Bell, 1997). Therefore, the mouth parts of one nymph in amber were reconstructed (Figure 7). Our results suggest that the mouth parts of the fossil nymphs do not appear to be specialised for this kind of feeding.

Another aspect worth mentioning is that the maxillary palps are well-developed and show an advanced, most likely fully functional, state of 
development. Maxillary palps possess contact-chemosensory (gustatory) capabilities. These might have served these nymphs as a sensory structure for keeping in touch with their siblings. Even longer palps seem to play an important role for communication in termites (Vršanský, 2010). For a clear statement about the correlation between the length of maxillary palps and possible chemosensory capabilities, analysing number, distribution, and identification of sensilla types would be necessary, but this point could not be resolved in the present study.

In summary, there are some morphological indications that the nymphs in amber were depending on parental care. These include the morphology of antennae, cerci and maxillary palps and the absence of pigmentation and presumably of eyes.

\section{CONCLUSIONS}

Our investigation of a single piece of amber with 13 cockroach nymphs reveals that: 1) A wide range of techniques is necessary to extract the largest possible amount of preserved details; 2) The specimens could represent a case of a group of blattodean nymphs hatching from an ootheca, which would represent the first fossil record of such a process, and 3) alternatively, the fossil could represent a case of social interaction (nymphal gregarism and/or extended parental care), which would likewise represent the first case of a fossil record of this behaviour in non-termite cockroaches.

\section{ACKNOWLEDGEMENTS}

This study benefited from the help of various persons and institutions. We are grateful to $A$. Bush (University of Connecticut, USA) and to two anonymous reviewers for helpful comments which improved the manuscript. We thank M. Nose, Munich, Germany, who helped in the collections and facilitated the loan of the specimen BSPG 1967 XX. We also thank R. Jahnke (University of Greifswald, Germany) for providing specimens of Blaberus craniifer and Periplaneta americana. We thank P. Mayer, Field Museum Chicago, for the loan of the specimen PE 61065. G.T. Haug (Neuried, Germany) is thanked for the documentation of the nymphs of $P$. americana. L. Vilhelmsen and $\mathrm{J}$. Olesen (both Natural History Museum of Denmark, Copenhagen) provided access to the amber collection of the museum and to technical equipment and helped with work in the collection. MKH was kindly funded by a grant from the European Commis- sion's (FP 6) Integrated Infrastructure Initiative programme SYNTHESYS (DK-TAF-3895). She is currently supported by the Studienstiftung des Deutschen Volkes. We furthermore thank the German Academic Exchange Service (DAAD), Alexander von Humboldt Foundation and German Research Foundation for funding (DFG Ha 6300/31; DFG INST 292/119-1 FUGG; DFG INST 292/ 120-1 FUGG). $\mathrm{CH}$ and JTH thank J. Matthias Starck (LMU Munich, Germany) for his support. We furthermore express our thanks to all people indirectly supporting our work by providing open source, open access or low cost software, such as Drishti, OpenOffice, Blender, Image Analyzer, and CombineZM/ZP.

\section{REFERENCES}

Ame, J.M., Rivault, C., and Deneubourg, J.L. 2004. Cockroach aggregation based on strain odour recognition. Animal Behaviour, 68(4):793-801.

Anisyutkin, L.D., Grachev, V.G., Ponomarenko, A.G., Rasnitsyn, A.P., and Vršansky, P. 2008. Fossil insects in the Cretaceous mangrove facies of southern Negev, Israel, p. 190-223. In Krassilov, V. and Rasnitsyn, A. (eds.), Plant-arthropod Interactions in the Early Angiosperm History: Evidence from the Cretaceous of Israel. Pensoft, Sofia, Moscow.

Arillo, A. 2007. Paleoethology: fossilized behaviours in amber. Geologica Acta, 5(2):159.

Bell, W.J., Parsons, C., and Martinko, E.A. 1972. Cockroach aggregation pheromones: analysis of aggregation tendency and species specificity (Orthoptera: Blattidae). Journal of the Kansas Entomological Society, 45:414-421.

Bell, W.J., Roth, L.M., and Nalepa, C.A. 2007. Cockroaches: Ecology, Behavior, and Natural History. JHU Press, Baltimore.

Béthoux, O., Klass, K.-D., and Schneider, J.W. 2009. Tackling the "Protoblattoidea problem": Revision of Protoblattinopsis stubblefieldi (Dictyoptera; Late Carboniferous). European Journal of Entomology, 106(1):145-152.

Beutel R.G. and Gorb, S. 2006. A revised interpretation of the evolution of attachment structures in Hexapoda (Arthropoda), with special emphasis on Mantophasmatodea. Arthropod Systematics and Phylogeny, 64:3-25.

Bohn, H. and Klass, K.-D. 2003. Dictyoptera, Ordnungen 13-15, p. 181-182. In Dathe, H.H. (ed.), Lehrbuch der Speziellen Zoologie, Band I: Wirbellose Tiere, 5. Teil: Insecta. Spektrum, Heidelberg, Berlin. (in German)

Braddy, S.J. and Briggs, D.E.G. 2002. New Lower Permian nonmarine arthropod trace fossils from New Mexico and South Africa. Journal of Paleontology, 76(3):546-557.

Burk, T. and Bell, W.J. 1973. Cockroach aggregation pheromone: inhibition of locomotion (Orthoptera: 
Blattidae). Journal of the Kansas Entomological Society, 46:36-41.

Cleland, C.E. 2002. Methodological and epistemic differences between historical science and experimental science. Philosophy of Science, 69(3):447-451.

Danforth, B.N., Conway, L., and Ji, S. 2003. Phylogeny of eusocial Lasioglossum reveals multiple losses of eusociality within a primitively eusocial clade of bees (Hymenoptera: Halictidae). Systematic Biology, 52(1):23-36.

Djernæs, M., Klass, K.-D., Picker, M.D., and Damgaard, J. 2012. Phylogeny of cockroaches (Insecta, Dictyoptera, Blattodea), with placement of aberrant taxa and exploration of out-group sampling. Systematic Entomology, 37:65-83.

Fortey, R.A. and Hughes, N.C. 1998. Brood pouches in trilobites. Journal of Paleontology, 72:638-649.

Garwood, R. and Sutton, M. 2010. X-ray micro-tomography of Carboniferous stem-Dictyoptera: new insights into early insects. Biology Letters, 6(5):699-702.

Grandcolas, P. 1996. The phylogeny of cockroach families: a cladistic appraisal of morpho-anatomical data. Canadian Journal of Zoology, 74(3):508-527.

Grandcolas, P. 1998. The evolutionary interplay of social behavior, resource use and anti-predator behavior in Zetoborinae+ Blaberinae+ Gyninae+ Diplopterinae cockroaches: a phylogenetic analysis. Cladistics, 14(2):117-127.

Grimaldi, D.A. and Engel, M. 2005. Evolution of the Insects. Cambridge University Press, New York.

Hädicke, C.W., Haug, C., and Haug, J.T. 2013. Adding to the few: a tomocerid collembolan from Baltic amber. Palaeodiversity, 6:149-156.

Haug, C., Mayer, G., Kutschera, V., Waloszek, D., Maas, A., and Haug, J.T. 2011. Imaging and documenting gammarideans. International Journal of Zoology, 2011:380829. doi:10.1155/2011/380829

Haug, C., Nyborg, T., and Vega, F.J. 2013a. An exceptionally preserved upogebiid (Decapoda: Reptantia) from the Eocene of California. Boletin de la Sociedad Geológica Mexicana, 6:235-248.

Haug, C., Shannon, K.R., Nyborg, T., and Vega, F.J. 2013b. Isolated mantis shrimp dactyli from the Pliocene of North Carolina and their bearing on the history of Stomatopoda. Bolétin de la Sociedad Geológica Mexicana, 65:273-284.

Haug, C. and Haug, J.T. 2014. Defensive enrolment in mantis shrimp larvae (Malacostraca: Stomatopoda). Contributions to Zoology, 83:185-194.

Haug, J.T., Audo, D., Charbonnier, S., Palero, F., Petit, G., Abi Saad, P., and Haug, C. in press. The evolution of a key character, or how to evolve a slipper lobster. Arthropod Structure \& Development.

Haug, J.T., Briggs, D.E.G., and Haug, C. 2012b. Morphology and function in the Cambrian Burgess Shale megacheiran arthropod Leanchoilia superlata and the application of a descriptive matrix. BMC Evolutionary Biology, 12(1):162.
Haug, J.T., Caron, J.-B., and Haug, C. 2013a. Demecology in the Cambrian: synchronized molting in arthropods from the Burgess Shale. BMC Biology, 11:64.

Haug, J.T., Hädicke, C.W., Haug, C., and Hörnig, M.K. 2015. A possible hatchling of a jumping bristle tail in 50 million years old amber. Neues Jahrbuch für Geologie und Paläontologie - Abhandlungen, 278(2):191199.

Haug, J.T., Haug, C., and Ehrlich, M. 2008. First fossil stomatopod larva (Arthropoda: Crustacea) and a new way of documenting Solnhofen fossils (Upper Jurassic, Southern Germany). Palaeodiversity, 1:103-109.

Haug, J.T., Haug, C., Kutschera, V., Mayer, G., Maas, A., Liebau, S., Castellani, C., Wolfram, U., Clarkson, E.N.K., and Waloszek, D. 2011. Autofluorescence imaging, an excellent tool for comparative morphology. Journal of Microscopy, 244:259-272.

Haug, J.T., Haug, C., Maas, A., Kutschera, V., and Waloszek, D. 2010. Evolution of mantis shrimps (Stomatopoda, Malacostraca) in the light of new Mesozoic fossils. BMC Evolutionary Biology, 10(1):290.

Haug, J.T., Haug, C., Schweigert, G., and Sombke A. 2014. The evolution of centipede venom claws Open questions and possible answers. Arthropod Structure \& Development, 43:5-16.

Haug, J.T., Mayer, G., Haug, C., and Briggs, D.E.G. 2012c. A Carboniferous non-onychophoran lobopodian reveals long-term survival of a Cambrian morphotype. Current Biology, 22:1673-1675.

Haug, J.T., Müller, C.H.G., and Sombke, A. 2013b. A centipede nymph in Baltic amber and a new approach to document amber fossils. Organisms Diversity \& Evolution, 13(3):425-432.

Haug, J.T., Waloszek, D., Maas, A., Liu, Y., and Haug, C. 2012a. Functional morphology, ontogeny and evolution of mantis shrimp-like predators in the Cambrian. Palaeontology, 55(2):369-399.

Hennig, W. 1969. Die Stammesgeschichte der Insekten. Waldemar Kramer, Frankfurt am Main. (in German)

Hockman, D., Picker, M.D., Klass, K.-D., and Pretorius, L. 2009. Postembryonic development of the unique antenna of Mantophasmatodea (Insecta). Arthropod Structure \& Development, 38(2):125-133.

Hörnig, M.K., Haug, C., and Haug, J.T. 2013. New details of Santanmantis axelrodi and the evolution of the mantodean morphotype. Palaeodiversity, 6:157-168.

Hörnig, M.K., Haug, C., Herd, K.J., and Haug, J.T. 2014. New insights into dictyopteran early development: smallest Palaeozoic roachoid nymph found so far. Palaeodiversity, 7:159-165.

Ingram, M.J., Stay, B., and Cain, G.D. 1977. Composition of milk from the viviparous cockroach, Diploptera punctata. Insect Biochemistry, 7(3):257-267.

Ishii, S. and Kuwahara, Y. 1967. An aggregation pheromone of the German cockroach Blattella germanica L. (Orthoptera: Blattellidae). Applied Entomology and Zoology, 2:203-217. 
Ishii, S. and Kuwahara, Y. 1968. Aggregation of German cockroach Blattella germanica nymphs. Experientia, 24:88-89.

Jeram, A.J., Selden, P.A., and Edwards, D. 1990. Land animals in the Silurian: arachnids and myriapods from Shropshire, England. Science, 250(4981):658661.

Johnson, E.W., Briggs, D.E.G., Suthren, R.J., Wright, J.L., and Tunnicliff, S.P. 1994. Non-marine arthropod traces from the subaerial Ordovician Borrowdale volcanic group, English Lake District. Geological Magazine, 131(3):395-406.

Klass, K.-D. 1998. The ovipositor of Dictyoptera (Insecta): Homology and ground-plan of the main elements. Zoologischer Anzeiger, 236:69-101.

Klass, K.-D., Matushkina, N., and Kaidel, J. 2012. The gonangulum a reassessment of its morphology, homology, and phylogenetic significance. Arthropod Structure \& Development, 41:373-394.

Klass, K.-D. and Meier, R. 2006. A phylogenetic analysis of Dictyoptera (Insecta) based on morphological characters. Entomologische Abhandlungen, 63(12):3-50.

Kranz, B.D., Schwarz, M.P., Morris, D.C., and Crespi, B.J. 2002. Life history of Kladothrips ellobus and Oncothrips rodwayi: insight into the origin and loss of soldiers in gall-inducing thrips. Ecological Entomology, 27(1):49-57.

Laurentiaux, D. 1960. La reproduction chez les Insectes blattaires du Carbonifère: facteurs du panchronisme et classification naturelle de l'ordre. Bulletin de la Société Géologique de France, 1(7):759-766. (In French)

Legendre, F., D'Haese, C.A., Deleporte, P., Pellens, R., Whiting, M.F., Schliep, K., and Grandcolas, P. 2014. The evolution of social behaviour in Blaberid cockroaches with diverse habitats and social systems: phylogenetic analysis of behavioural sequences. Biological Journal of the Linnean Society, 111(1):58-77.

Legendre, F., Pellens, R., and Grandcolas, P. 2008. A comparison of behavioural interactions in solitary and presocial Zetoborinae cockroaches (Blattaria, Blaberidae). Journal of Insect Behavior, 21(5):351365.

Leoncini, I. and Rivault, C. 2005. Could species segregation be a consequence of aggregation processes? Example of Periplaneta americana (L.) and $P$. fuliginosa (Serville). Ethology, 111(5):527-540.

Minter, N.J., Mángano, M.G., and Caron, J.B. 2012. Skimming the surface with Burgess Shale arthropod locomotion. Proceedings of the Royal Society B: Biological Sciences, 279(1733):1613-1620.

Nalepa, C.A. and Bell, W.J. 1997. Postovulation parental investment and parental care in cockroaches, p. 2651. In Choe, J.C. (ed.), The Evolution of Social Behaviour in Insects and Arachnids. Cambridge University Press, Cambridge.

Nalepa, C.A. and Lenz, M. 2000. The ootheca of Mastotermes darwiniensis Frogatt (Isoptera: Mastoter- mitidae): homology with cockroaches oothecae. Proceedings of the Royal Society B: Biological Sciences, 267:1809-1813.

Park, Y.C., Grandcolas, P., and Choe, J.C. 2002. Colony composition, social behavior and some ecological characteristics of the Korean wood-feeding cockroach (Cryptocercus kyebangensis). Zoological Science, 19(10):1133-1139.

Pellens, R., D'Haese, C.A., Bellés, X., Piulachs, M.D., Legendre, F., Wheeler, W.C., and Grandcolas, P. 2007. The evolutionary transition from subsocial to eusocial behaviour in Dictyoptera: phylogenetic evidence for modification of the "shift-in-dependentcare" hypothesis with a new subsocial cockroach. Molecular Phylogenetics and Evolution, 43(2):616626.

Pellens, R. and Grandcolas, P. 2003. Living in Atlantic forest fragments: life habits, behaviour, and colony structure of the cockroach Monastria biguttata (Dictyoptera, Blaberidae, Blaberinae) in Espirito Santo, Brazil. Canadian Journal of Zoology, 81(12):19291937.

Poinar, G. Jr. 2010. Palaeoecological perspectives in Dominican amber. Annales de la Société Entomologique de France, 46:23-52.

Pruvost, P. 1919. Introduction à l'étude du terrain houiller du Nord et du Pas-de-Calais. La faune continentale du terrain houiller du Nord de la France. Mémoires pour servir à l'explication de la carte géologique détaillée de la France, Paris.

Pruvost, P. 1930. Description de la faune continentale du terrain houiller de la Belgique. Mémoires du Musée d'Histoire Naturelle de Belgique, 44:105-282.

Rasnitsyn, A.P. and Quicke, D.L.J. 2002. History of Insects. Kluwer, Dordrecht, Boston, and London.

Rosenberg, J. 2009. Die Hundertfüßer: Chilopoda. Westarp-Wissenschaften, Hohenwarsleben. (In German)

Roth, L.M. and Stay, B. 1961. Oöcyte development in Diploptera punctate (Eschscholtz) (Blattaria). Journal of Insect Physiology, 7(3):186-202.

Sakuma, M. and Fukami, H. 1990. The aggregation pheromone of the German cockroach, Blattella germanica (L.) (Dictyoptera: Blattellidae): isolation and identification of the attractant components of the pheromone. Applied Entomology and Zoology, 25:355-368.

Schlee, D. 1980. Bernstein-Raritäten: Farben, Strukturen, Fossilien, Handwerk; aus der Bernsteinsammlung des Staatlichen Museums für Naturkunde in Stuttgart; mit einem kulturhistorischen Anhang. Staatliches Museum für Naturkunde, Stuttgart. (In German)

Shear, W.A. and Edgecombe, G.D. 2010. The geological record and phylogeny of the Myriapoda. Arthropod Structure \& Development, 39(2):174-190.

Shear, W.A., Jeram, A.J., and Selden, P. 1998. Centiped legs (Arthropoda, Chilopoda, Scutigeromorpha) from the Silurian and Devonian of Britain and the Devo- 
nian of North America. American Museum Novitates, 3231:1-16.

Siveter, Da.J., Siveter, De.J., Sutton, M.D., and Briggs, D.E.G. 2007. Brood care in a Silurian ostracod. Proceedings of the Royal Society B: Biological Sciences, 274(1609):465-469.

Sombke, A., Lipke, E., Michalik, P., Uhl, G., and Harzsch, S. 2015. Potential and limitations of X-ray micro-computed tomography in arthropod neuroanatomy - a methodological and comparative survey. The Journal of Comparative Neurology, 523(8):1281-1295.

Tallamy, D.W. and Wood, T.K. 1986. Convergence patterns in subsocial insects. Annual Review of Entomology, 31(1):369-390.

Vršanský, P. 2010. Cockroach as the earliest eusocial animal. Acta Geologica Sinica, English Edition, 84(4):793-808.
Ware, J.L., Grimaldi, D.A., and Engel, M.S. 2010. The effects of fossil placement and calibration on divergence times and rates: An example from the termites (Insecta: Isoptera). Arthropod Structure \& Development, 39:204-219.

Weitschat, W. and Wichard, W. 2002. Atlas of Plants and Animals in Baltic Amber. Verlag Dr. Friedrich Pfeil, München.

Weitschat, W. and Wichard, W. 2010. Baltic amber, p. 80-115. In Penney, D. (ed.), Biodiversity of Fossils in Amber from the Major World Deposits. Siri Scientific Press, Manchester.

Williford, A., Stay, B., and Bhattacharya, D. 2004. Evolution of a novel function: nutritive milk in the viviparous cockroach, Diploptera punctata. Evolution and Development, 6(2):67-77. 
HÖRNIG ET AL.: AMBER COCKROACH NYMPHS

\section{APPENDIX 1.}

Descriptive matrix of Periplaneta americana and of BSPG 1967 XX - available in PDF and Excel formats (see palaeo-electronica.org/content/2016/1405-amber-cockroach-nymphs). 